\title{
THE REPRESENTATION VICTIMS OF VIOLENCE IN TRIBUN TIMUR ONLINE NEWS TEXT: CRITICAL DISCOURSE ANALYSIS
}

\author{
A. Yusdianti Tenriawali Universitas Iqra Buru \\ Jl. Prof. DR. H. A.R. Bassalamah, SE.,M.Si, Namlea, Kab. Buru \\ Pos-el: tenriawali@gmail.com
}

\begin{abstract}
This study discussed about the representation victims of violence in the online news text of Tribun Timur online news. The purpose of this study was identifing the form of discourse strategies which was used by journalists to positioned the victims of violence in the news text on Makassar.tribunnews.com site. This research wasqualitative research by using descriptive method. this research used critical discourse analysis approach. Sources of the data in this study was taken from the text of violence news- that represented the victims of violence- which had written in the online news site Tribun Timur. The data collection in this research were using documentation and record technique. The results showed that the form of news language was the word that contained inclusive discourse strategy such asstrategy of nomination and identification. In the news texts, the nomination strategy appeared in male violance victims as natural while identification strategy appeared in women violence victims as weakness one.e. Male victims, in the online news text,tended to be more protected than female. It had indicated that Tribun Timur journalists tended to adhere the ideology of patriarchy.
\end{abstract}

Keywords: CDA, inclusive, news. 


\section{INTRUDACTION}

Secara faktual fenomena tindak kekerasan masih saja terjadi dalam kehidupan masyarakat, padahal apa pun ajaran agama dan kepercayaan yang ada di dunia ini tidak akan pernah memberikan legitimasi pada tindak kekerasan. Sejalan dengan dinamika perkembangan peradaban manusia yang semakin maju, seyogyanya segala bentuk tindakan kekerasan mestinya tidak perlu terjadi atau disengaja muncul (violence by design), sebab segala bentuk tindakan kekerasan tidak mencerminkan tindakan manusia yang berbudaya (Hufad, 2003:1). Bentuk tindakan kekerasan dari seseorang kepada orang lain, dari suatu kelompok kepada kelompok lainnya dengan motif apapun tergolong sebagai perilaku menyimpang. Hal ini tidak bisa dibenarkan menurut normanorma sosial. Namun fenomena tindakan kekerasan yang dilakukan oleh individu, kelompok, ataupun institusi sosial hingga kini tetap saja berlangsung.

Istilah kekerasan digunakan untuk menggambarkan perilaku baik yang terbuka (overt) maupun tertutup (covert), yang bersifat menyerang (offensive) atau bertahan (defensive) yang disertai penggunaan kekuatan kepada orang lain (Suwarno, 2012:48). Ada dua hal mendasar yang perlu kita cermati ketika berbicara tentang kekerasan atau budaya kekerasan dalam masyarakat, yaitu; penggunaan kekerasan dalam masyarakat, sebagai contoh: pembunuhan atas nama Negara atau 'Tuhan atau Agama', dan legitimasi terhadap penggunaan kekerasan itu (Galtung, 2002:184).

Kekerasan fisik dan kekerasan simbolik sudah menjadi bagian kehidupan manusia. Hal tersebut terlihat pada banyaknya berita yang menunjukkan kekerasan dalam media massa, sebagai contoh pada Juni tahun 2015 muncul berita pembunuhan Engeline yang banyak menarik perhatian masyarakat. Mayat Engeline ditemukan di sekitar rumah ibu angkatnya. Berdasarkan penyelidikan polisi diketahui bahwa sebelum meninggal, Engeline mengalami penganiayaan. Berita penganiayaan yang menarik perhatian publik kembali muncul pada tahun 2016. Pada akhir tahun 2016, media massa khususnya situs berita daring kembali diramaikan dengan berita penganiayaan yang dilakukan oleh seorang pegawai Mahkamah Agung pada seorang polisi. Penganiayaan tersebut disebabkan karena pelaku penganiayaan tidak terima mobilnya yang telah melanggar jalur lalu lintas diberhentikan oleh polisi. Banyak dan beragamnya berita yang bertema kekerasan dalam media massa, menjadikan media massa sebagai salah satu sumber informasi aktual mengenai peristiwa kekerasan yang terjadi dalam masyarakat.

Salah satu wujud ketimpangan sosial yang sering menjadi sorotan di media massa dewasa ini adalah ketimpangan sosial yang menimpa para korban kekerasan pada pemberitaan di media massa. Tak jarang, media massa menyuguhkan pemberitaan yang berisi penyiksaan, pemerkosaan, pembunuhan, dan lain-lain, yang menggambarkan bahwa para korban yang mengalami kekerasan tersebut pantas mengalami kekerasan tersebut, ataupun kekerasan yang dialami para korban terjadi karena kesalahan korban sendiri.

Penggambaran media massa akan sosok korban kekerasan, khususnya pada perempuan dan anak-anak yang jika dilihat dari perspektif kesetaraan gender, telah terjadi praktik diskriminasi yang dilakukan oleh media massa. Perempuan dan anak- anak sebagai sosok yang dianggap lemah, dicitrakan pantas atau sudah biasa menjadi korban kekerasan, sehingga pelaku yang melakukan 
tindak kekerasan pada perempuan dan anak-anak dianggap wajar jika melakukan tindak kekerasan tersebut.

Namun, realita saat ini, yang menjadi korban kekerasan bukan hanya perempuan dan anakanak, tetapi laki-laki pun telah menjadi korban kekerasan. Banyaknya berita dalam media massa yang memberitakan tentang laki-laki yang menjadi korban kekerasan, menjadi bukti bahwa korban kekerasan tidak hanya terjadi pada perempuan dan anak-anak, tetapi terjadi juga pada laki-laki. Fenomena tersebut menjadi menarik, sebab bagaimana cara media massa menggambarkan sosok laki-laki yang menjadi korban kekerasan kemungkinan besar akan berbeda dengan cara media massa menggambarkan korban kekerasan yang dialami perempuan dan anak-anak.

Hal tersebut didasari pandangan umum bahwa laki-laki tidak mungkin menjadi korban sebab laki-laki dianggap memiliki kekuatan, sedangkan perempuan dan anak-anak yang dianggap lemah sehingga wajar menjadi korban. Bagaimana media massa menggambarkan atau merepresentasikan korban kekerasan dalam berita pada berita. Bagaimana cara media massa, khususnya dalam situs berita daring koran Tribun Timur merepresentasikan korban kekerasan yang dialami oleh perempuan dan laki-laki, apakah terdapat perbedaan representasi jika korban kekerasan tersebut perempuan atau laki-laki merupakan fokus penelitian ini.

Untuk melihat bagaimana representasi korban kekerasan pada situs berita daring Tribun Timur, maka peneliti menggunakan analisis wacana kritis dengan model Theo Van Leeuwen. Analisis wacana kritis dengan model Theo Van Leeuwen yang digunakan dalam penelitian ini merupakan model yang telah dikembangkan oleh Eriyanto. Penelitian mengenai representasi korban kekerasan telah banyak dilakukan, diantaranya Suganda, dkk. (2007:5) yang menunjukkan bahwa media massa nasional merepresentasikan sosok Tenaga Kerja Wanita Indonesia sebagai sosok yang marginal, tidak mempunyai kekuatan dan kekuasaan, kampungan, tak berpendidikan, miskin, bodoh, dan lain-lain. Setiawan (2011:14) yang meneliti pemberitaan kekerasan berbasis gender di surat kabar harian suara merdeka menyimpulkan bahwa surat kabar Harian Suara Merdeka telah secara tidak adil menginformasikan berita kekerasan terhadap perempuan dengan menempatkan perempuan sebagai objek penderita. Hasanah (2013:159) yang meneliti kekerasan terhadap perempuan dan anak dalam rumah tangga perspektif pemberitaan media menunjukkan bahwa opini dan peran media dirasa cukup besar dalam mengonstruksi realitas secara sosial.

Juditha (2015:15) meneliti tentang Dilematis Media dalam Pemberitaan Konflik dan Kekerasan. Hasil penelitian menunjukkan bahwa Media massa dinilai memiliki potensi fungsional karena berpotensi untuk menebar semangat perdamaian dan meredakan konflik. Sebaliknya media massa juga dinilai memiliki potensi untuk memperkeruh atau bahkan memicu konflik yang berkepanjangan. Serta Fauziah \& Tamampil (2015:131) yang meneliti tentang representasi perempuan dalam pemberitaan KDRT di media massa pada masyarakat di wilayah jakarta. Dari hasil penelitian dapat disimpulkan bahwa dalam berita yang terkait dengan KDRT merepresentasikan perempuan (istri) sebagai objek. Teks berita tersebut menjadi bias dalam merepresentasikan perempuan karena dalam teks berita tersebut suara perempuan (istri) tidak benar-benar ditunjukkan. 
Dari berbagai penelitian di atas, terlihat bahwa yang menjadi fokus penelitian pada hampir semua penelitian terdahulu korban perempuan. Mengingat bahwa yang menjadi korban kekerasan tidak hanya perempuan namun juga laki-laki, maka penelitian ini akan melihat bagaimana representasi laki-laki dan perempuan sebagai korban kekerasan dalam situs berita daring Tribun Timur. Berdasarkan latar belakang tersebut, pokok permasalahan dalam penelitian ini adalah Bagaimanakah bentuk strategi wacana berita yang digunakan dalam merepresentasikan korban kekerasan pada situs makassar.tribunnews.com? tujuan penelitian ini untuk mengidentifikasi bentuk kebahasaan strategi wacana yang digunakan wartawan dalam memosisikan korban kekerasan dalam teks berita pada situs makassar.tribunnews.com.

Melalui penelitian ini, peneliti berupaya melengkapi berbagai penelitian tentang korban kekerasan di media massa yang telah dilakukan peneliti sebelumnya dengan memasukkan korban laki-laki sebagai objek penelitian tindak kekerasan. Penelitian ini belum mencakup analisis tentang efek teks berita yang ditimbulkan atau dihasilkan dalam masyarakat. 


\section{DAFTAR PUSTAKA}

Umar, A., Madani, M., Farida, U., Yusriadi, Y., Tamsa, H., Yahya, M., ... \& Sakkir, G. (2019). One-Stop Service Policy as a Bureaucratic Reform in Indonesia. Academy of Strategic Management Journal.

Bin-Tahir, S. Z., Bugis, R., Masniati, A., Tenriawali, A. Y., Azwan, A., \& Oktavianti, D. C. (2020, January). The Role of Local Language in Intercultural Communication among Societies of Buru Island. In Proceeding of USN Kolaka-ADRI International Conference on Sustainable Coastal-Community Development (Vol. 1).

La Jati Buton, M. O., Bula, M., Djunaidi, F. G., Amir, N. F., Umarella, U., La Husni Buton, M., ... \& Tenriawali, A. Y. The Effect Of Nasa Liquid Organic Fertilizer Concentration And Planting Distance To Growth And Production Of Beans.

Karim, K., Maknun, T., \& Abbas, A. (2019). PRAANGGAPAN DALAM PAMFLET SOSIALISASI PELESTARIAN LINGKUNGAN DI KABUPATEN WAKATOBI. JURNAL ILMU BUDAYA, 7(2), 241-247.

Bin-Tahir, S. Z., Bugis, R., Masniati, A., Tenriawali, A. Y., Azwan, A., \& Oktavianti, D. C. (2020, January). The Role of Local Language in Intercultural Communication among Societies of Buru Island. In Proceeding of USN Kolaka-ADRI International Conference on Sustainable Coastal-Community Development (Vol. 1).

Sahid, A., Amirullah, I., Azis, A., Rachman, A. A., \& Bin-Tahir, S. Z. (2019, November). Application of Bureaucratic Accountability in Public Service. In Eastern Regional Organization for Public Administration Conference (EROPA 2018). Atlantis Press.

Mufidah, N., Suryawati, D., Sa'adah, N., \& Tahir, S. Z. B. (2019). LEARNING ARABIC WRITING SKILL BASED ON DIGITAL PRODUCTS. Ijaz Arabi Journal of Arabic Learning, 2(2).

Farida, U., \& Bin-Tahir, S. Z. (2019, October). Bureaucratic reform of tourism sector public services in Tana Toraja Regency. In IOP Conference Series: Earth and Environmental Science (Vol. 340, No. 1, p. 012045). IOP Publishing.

Bin-Tahir, S. Z., Atmowardoyo, H., Dollah, S., Rinantanti, Y., \& Suriaman, A. (2018). MULTILINGUAL AND MONO-MULTILINGUAL STUDENTS'PERFORMANCE IN ENGLISH SPEAKING. Journal of Advanced English Studies, 1(2), 32-38.

Bin-Tahir, S. Z., Suriaman, A., \& Rinantanti, Y. (2019). Designing English Syllabus for Multilingual Students at Pesantren Schools. Asian EFL Journal, 23(3.3), 5-27.

Bin Tahir, S. Z. (2015). Multilingual behavior of Pesantren IMMIM students in Makassar. Asian EFL Journal, 86, 45-64.

Amri, M., Afifuddin, A., \& Bin-Tahir, S. Z. (2018). Religious Pluralism of the Indonesian Traditional Islamic Education Institutions. The Journal of Social Sciences Research, 4(12), 446-450.

Bin Tahir, S. Z. (2017). Multilingual teaching and learning at Pesantren Schools in Indonesia. Asian EFL Journal, 89, 74-94.

Umanailo, M. C. B., Bin-Tahir, S. Z., Mukaddar, M., Kubangun, H., Hamiru, H., Sangadji, M. F., ... \& Hanapi, H. (2018). Economics And Survival Moral Strategies Of The Upland Rice Farmers. In International Conference on Life, Innovation Change and Knowledge (Vol. 1, No. 1). 
Bin-Tahir, S. Z., Saidah, U., Mufidah, N., \& Bugis, R. (2018). The impact of translanguaging approach on teaching Arabic reading in a multilingual classroom. Ijaz Arabi Journal of Arabic Learning, 1(1).

Bin-Tahir, S. Z., Bugis, R., \& Tasiana, R. (2017). Intercultural Communication of a Multicultural Family in Buru Regency. Lingual: Journal of Language and Culture, 9(2), 8.

Nurhayati, N., \& Said, I. (2019). Emosi Verbal Suku Bajo Sampela. Sosial Budaya, 16(2), 114-126.

Tenriawali, A. Y. (2018). Representasi korban kekerasan dalam teks berita daring Tribun Timur: analisis wacana kritis/A. Yusdianti Tenriawali.

La Jati Buton, M. O., Bula, M., Djunaidi, F. G., Amir, N. F., Umarella, U., La Husni Buton, M., ... \& Tenriawali, A. Y. The Effect Of Nasa Liquid Organic Fertilizer Concentration And Planting Distance To Growth And Production Of Beans.

Tahir, S. Z. B., Atmowardoyo, H., \& Dollah, S. (2018). Belajar Berbicara Multibahasa Uuntuk Santri Pesantren. Deepublish.

Djunaidi, F. G., Azwan, A. Y. T., Iye, R., \& bin Tahir, S. Z. Decks Range Gola Village Community Begun District Buton District North.

Mastuti, A. G., \& Bin-Tahir, S. Z. APPLYING THE UNIQUE TASKS IN MATHEMATICS CLASS.

Mufidah, N., Firdaus, U. Z., \& Tahir, S. Z. B. (2018). Model Pengayaan Tutor Bahasa: Studi pre-learning pada Shabahul Lughoh di Ma'had Sunan Ampel Al Aly. Jurnal At-Ta'dib Vol, 13(2).

Bin-Tahir, S. Z., Hanapi, H., Mufidah, N., Rahman, A., \& Tuharea, V. U. Revitalizing The Maluku Local Language In Multilingual Learning Model.

Bin Tahir, S. Z. (2013). Pengajaran Bahasa Inggris-Teaching English as World Language. Jakarta: Media Pustaka Qalam.

TAHIR, S. Z. A. B. (2017). Pengembangan Materi Multibahasa untuk Siswa Pesantren (Doctoral dissertation, Pascasarjana).

Bin Tahir, S. Z. (2013). Penggunaan Facebook Untuk Meningkatkan Kemampuan Menulis Teks Deskriptif Mahasiswa Fkip Jurusan Bahasa Inggris Di Universitas Iqra Buru. Jurnal Prospek, 15(1), 68-76.

Sam, B., Iye, R., Ohoibor, M., Umanailo, M. C. B., Rusdi, M., Rahman, A. B. D., \& Hajar, I. (2019). Female Feminism in the Customary Island of Buru. Int. J. Sci. Technol. Res, 8(8), 1877-1880.

Iye, R. (2018). Tuturan emosi mahasiswa kota baubau dalam ranah demonstrasi [emotional speech of the students in baubau city in the demonstration]. TOTOBUANG, 6 (1), 125, 138.

Iye, R., \& Susiati, S. (2018). NILAI EDUKATIF DALAM NOVEL SEBAIT CINTA DI BAWAH LANGIT KAIRO KARYA MAHMUD JAUHARI ALI (Educative Values in Sebait Cinta di Bawah Langit Kairo by Mahmud Jauhari Ali). Sirok Bastra, 6 (2), 185-191.

Susiati, S., Iye, R., \& Suherman, L. O. A. (2019). Hot Potatoes Multimedia Applications in Evaluation of Indonesian Learning In SMP Students in Buru District. ELS Journal on Interdisciplinary Studies in Humanities, 2(4), 556-570. 
Iye, R. Jl Prof Dr HAR Basalamah No, and Namlea-Kab Buru.". TUTURAN DALAM PROSESI LAMARAN PERNIKAHAN DI TOMIA KABUPATEN WAKATOBI." Kontemporer. Bandung: PT Remaja.

Susiati, S., \& Iye, R. (2018). Kajian Geografi Bahasa dan Dialek di Sulawesi Tenggara: Analisis Dialektometri. Gramatika: Jurnal Ilmiah Kebahasaan dan Kesastraan, 6(2), 137-151.

Susiati, S., \& Iye, R. (2018). Kajian Geografi Bahasa dan Dialek di Sulawesi Tenggara: Analisis Dialektometri. Gramatika: Jurnal Ilmiah Kebahasaan dan Kesastraan. 6 (2), 137-151.

Iye, R., Susiati, S., \& Karim, K. (2020). Citra Perempuan dalam Iklan Sabun Shinzui. Sang Pencerah: Jurnal Ilmiah Universitas Muhammadiyah Buton, 6(1), 1-7.

Iye, R. (2018). Tuturan dalam Prosesi Lamaran Pernikahan di Tomia Kabupaten Wakatobi. Jurnal Totobuang, 6(2).

Iye, R. Harziko. NILAI-NILAI MORAL DALAM TOKOH UTAMA PADA NOVEL SATIN MERAH KARYA BRAHMANTO ANINDITO DAN RIE YANTI. TELAGA BAHASA,(7), 2, 195-206.

Susiati, Y. T. Risman Iye. A. Kesantunan Imperatif Bahasa Indonesia Suku Bajo Sampela: Balai Pembinaan dan Pengembangan Bahasa. 2018. Kongres Bahasa Indonesia (No. 12, pp. 1-6). Report.

UNIQBU, P. (2019). TUTURAN EMOSI MAHASISWA KOTA BAU BAU.

PSP2M, T., \& Iye, R. TUTURAN EMOSI MAHASISWA KOTA BAU BAU.

Umanailo, M. C. B., Hentihu, I., Umanailo, R., Nawawi, M., Pulhehe, S., Ohoibor, M., ... \& Bugis, R. I. K. I. (2018). Pemahaman Untuk Desa.

Umanailo, M. Chairul Basrun, Idrus Hentihu, Rosita Umanailo, Mansyur Nawawi, Sukainap Pulhehe, Mirja Ohoibor, Mohammad Faisal Sangadji et al. "Pemahaman Untuk Desa." (2018).

BURU, U. I. MODEL KOOPERATIF LEARNING TIPE STAD DALAM MENINGKATKAN KEMAMPUAN MENGAPRESIASI CERITA FIKSI DI SD NEGERI 1 NAMLEA.

Iye, R. (2018). Tuturan emosi mahasiswa kota baubau dalam ranah demonstrasi.

No, J. S. Q., Baruga, K. K., Bassalama, J. P. A., \& Si, M. PRAANGGAPAN PAMFLET SOSIALISASI PELESTARIAN LINGKUNGAN DI KABUPATEN WAKATOBI.

Djunaidi, F. G., Azwan, A. Y. T., Iye, R., \& bin Tahir, S. Z. Decks Range Gola Village Community Begun District Buton District North.

Buru, K. M. S. PENGARUH MOTIVASI BELAJAR DI SMA NEGERI 2 BURU.

No, J. S. Q., Baruga, K. K., Bassalama, J. P. A., \& Si, M. PRAANGGAPAN PAMFLET SOSIALISASI PELESTARIAN LINGKUNGAN DI KABUPATEN WAKATOBI.

BURU, U. I. MODEL KOOPERATIF LEARNING TIPE STAD DALAM MENINGKATKAN KEMAMPUAN MENGAPRESIASI CERITA FIKSI DI SD NEGERI 1 NAMLEA.

YANTI, KBADANRI. "NILAI-NILAI MORAL DALAM TOKOH UTAMA PADA NOVEL SATIN MERAH." 
Buru, K. M. S. PENGARUH MOTIVASI BELAJAR DI SMA NEGERI 2 BURU.

Djunaidi, F. G., Azwan, A. Y. T., Iye, R., \& bin Tahir, S. Z. Decks Range Gola Village Community Begun District Buton District North.

Iye, R. DEIKSIS MASYARAKAT BONEGUNU KABUPATEN BUTON UTARA.

YANTI, K. NILAI-NILAI MORAL DALAM TOKOH UTAMA PADA NOVEL SATIN MERAH. 